\title{
Concerns of \\ Contemporary Adolescents
}

RichaRd SchMUCK

$I^{\mathrm{N}}$

$\mathbf{N}$ THIS PAPER, I will emphasize problems as seen by working and middle class adolescents with considerable economic security, little anxiety about survival, and generally healthy personalities. Youngsters of the working and middle-classes, though generally contented, healthy, and competent, do have realistic concerns which often keep them from fully realizing themselves intellectually and socially. These concerns are not focused on the tangible and the concrete, as they are for the impoverished youth of our inner cities and barren countryside. In contrast, working and middle-class youngsters are bothered by the complexities and conflicts in the interpersonal demands of the present and future-they are concerned with making sense out of the multiple demands of parents, teachers, and peers while trying to become an autonomous and integrated individual.

Each of the adolescent concerns presented below was derived from questionnaires systematically collected from three groups of teenagers, 30 participants in a weekend human relations laboratory sponsored by the Institute for Social Research and YWCA, ${ }^{1}$ about 200 youth of the Episcopalian church, and 15 Unitarian teenagers.

${ }^{1}$ Hawkinshire, F., (ed.), Parents, Teachers, and Youth: A Teenage Weekend Laboratory, Document No. 9 of Inter-Center Program on Children, Youth, and Family Life, Institute for Social Research, The University of Michigan, Ann Arbor, Michigan, 1962.

Richard Schmuck is study director in the Institute for Social Research and assistant professor of psychology at The University of Michigan. This paper is based on a presentation made on October 15, 1963 to the Clarenceville High School PTA, Livonia, Michigan. Special thanks are due to Mark Chesler, Ronald Lippitt, and Patricia Schmuck for their helpful criticisms of an earlier draft of this paper. 
The specific responses are grouped into more general categories of concern. In every case the listed concerns come directly from adolescents; they are not derived from a psychological theory. In the main, the concerns involve parents, teachers, and peers. Let us begin a description of the most common concerns with parents as viewed by the adolescent boy or girl.

\section{Concerns with Parents}

Adolescents view parents as the most significant figures in their lives. They usually refer to them whenever decisions they feel are important have to be made. Of all the concerns which the youngsters reported, over sixty-five per cent involved their parents. Although several hundred statements of problems with parents were collected, it was possible to organize almost all of them into four categories.

\section{Parents not discussing with the adolescent what he or she considers} important.

Some examples of statements about parents are: "They won't listen to me," "They think many of my wishes and fears are silly," "I often feel that I am not trusted and listened to by them," and "They treat me like a child, never listen to me." The adolescent who makes statements like these means that his parents and he are unable to communicate successfully; that the different generations cannot bridge the psychological gulf between them. These comments are seldom based on the youth's perceptions that his parents do not have enough time for him. Accurate communication and genuine empathy, not time spent, concern the adolescent.

Even a cursory analysis suggests that responsibility for unclear communication and an absence of empathy lies with both generations. On the one hand, parents often do not appreciate the importance to the adolescent of his own thoughts, feelings, and terminology; conversely adolescents have difficulty in perceiving the limits of their parents' knowledge about youth culture and become impatient with them too quickly. Often parents increase the gulf by failing to talk with the adolescent about values and personal controls. Because parents are looked to for guidance concerning important decisions, communication difficulties with them heighten the youth's anxieties about his autonomy. Adolescent anxieties over autonomy, as well as related fears of the parents concerning controls, complicate the youth's attempts to achieve individuality. 
2. Parents demanding that the adolescent's thoughts and activities be public.

Some of the youth interviewed, mostly girls, were distressed about a lack of privacy. They said such things as, "My parents always want to know what I'm doing and thinking," "My mother sometimes picks up the extension phone and listens to my telephone conversations with boys," and "My father asks my girl friends about what I do on dates." Here the concern primarily is with clandestine parental observations of activities with peers. Often, of course, the youngster suspects his parents of doing more of this than is actually the case. Nevertheless, this fairly typical perception, represented by about twenty per cent of the youth interviewed, eighty-five per cent of whom were girls, is representative of a basic problem of trust.

Parents and teenagers find difficulty in achieving a comfortable balance in sharing their public and private lives. This difficulty in sharing often leads to distrust between the generations. Some parents try to develop trust by imitating the behaviors of their adolescent son or daughter. These parents feel that trust can be established by using teenage jargon, by joining the screaming over the latest theatrical or musical rage, or by dressing as though they were seventeen. In attempting to establish trust by imitating youth, parents forfeit their status leaving the adolescent without clarity in his search for attractive and reachable adult models. Without active parental guidance, the adolescent has little sense of where he is headed, experiences disorganization and discouragement, and is easily manipulated by the fads and fancies of the day. Parents tend to establish trust when they respect adolescent privacy while showing an honest and sincere adult interest in what the adolescent believes and feels.

\section{Parents restricting dating patterns.}

Many of the girls (sixty per cent), but only a few of the boys (five per cent), discussed dating as a focus of conflict with parents. The girls mentioned such things as, "My mother doesn't allow me to date even though most of the other girls in my class date often" (a tenth grade girl), "My Dad gives me a hard time when I want to date a boy older than me," and "My father is always checking up on me when I'm out on a date." Comments like these demonstrate the importance of the adolescent girl's attempts to relate effectively to boys. In contrast to boys, for whom success in adult life depends largely on occupational adjustment, a satisfactory 
adulthood for girls depends much more on a healthy marriage. For adolescent girls, dating serves as a barometer of later happiness.

Although there is some pressure on girls to date early, the demands of the 1960's for specialized skills and advanced education increase the waiting period before marriage. One major consequence of this bind is that both parents and adolescent girls worry about the consequences of dating. The girl must date as a preparation for adulthood, but she must not go too far too soon with her dates. The anxieties raised by this dilemma manifest themselves often in a lessening of effective communication between the generations about romance and marriage.

Some parents unconsciously aggravate these adolescent concerns about dating and marriage. They dread the girl's eventual severance from home and respond by smothering her with affection and rigid controls. Fathers often react this way out of a fear that their daughter may be "ruined" by the "evil men" in the world. Some mothers fear that their child, male or female, will not be able to solve personal problems without parental guidance. In other families, the presence of an adolescent keeps the parents together. Such parents, out of anxiety over a loss of marital stability, work to keep the adolescent dependent on them. Parental over-control restrains the adolescent from doing what teachers and peers indirectly tell him to do-become an individual, rely on himself, become autonomous from his family, become competent on his own.

\section{Adolescent lacking respect for, and trust in, their parents.}

The most frequent concern for adolescent boys involves the integrity, trustworthiness, and forthrightness of their parents. Some boys say of their parents, "They say one thing and do another," "They are real phonies," and "They do not agree often on what they want me to do." Although comments like these occurred in only about twenty-five per cent of the boys interviewed, they were laden with feeling and must be considered as significant. The perceptions that parents are sometimes "phonies" leads to an alienation from adult modeling and often a destructive, extropunitive outpouring against adult society.

Some parents evoke such feelings through their own inconsistencies in decision-making about child-rearing. When one parent plays a minor role in the family vis-a-vis the youth, the adolescent becomes confused about parent expectations concerning his be- 
havior. The adolescent learns about this power discrepancy and plays one parent against the other. The family without a united front and shared responsibility in deciding important matters with the youth tend to be manipulated by him. Moreover, given these family experiences, the youth often has difficulty in adjusting to others, especially teachers and peers who are not so easily manipulated.

\section{Concerns with Teachers}

Teachers were the second most common group of people with whom adolescents had major concerns. At least forty per cent of the youth remarked about problems they have had with their teachers. Some of these were:

\section{Teachers not getting to know the students.}

The most frequent concern with teachers (about 20 per cent of the sample) had to do with a lack of intimacy and personal contact between the generations. Examples of comments which typified this concern were, "We get too little personal attention from our teachers," "Teachers don't care if they know you very well or not," and "Our teachers are like machines-you go to class and they 'spiel' out information." Adolescents making such statements are asking for some consideration and respect as persons.

Some teachers seemingly do not realize that an adolescent's perceptions of his own competence and effectiveness make up an integral part of his school motivation. Even where teachers are aware of this, they sometimes fail to appreciate that these self-perceptions can change from day to day, depending on the reflected appraisals received by the adolescent from important others. Since competence and achievement are valued so highly in contemporary society, the adolescent is especially sensitive to others' evaluations of his school performance. The teacher plays a special role in defining how competent or incompetent the adolescent is. Some teachers unknowingly deprive youth of their self-respect, confidence, and esteem. The more an adolescent is treated as incompetent, the more he will come to exhibit this prophecy; and, of course, conversely when he is given support and respect, he develops a more positive view of himself. The adolescent's concept of himself, especially in the areas of expertness and personal efficacy, is built up through the accumulated reflected appraisals of teachers with 
whom he comes in contact. A positive view of self facilitates high academic performance, while a negative view inhibits it.

\section{Teachers lacking interest in teaching and youth.}

About ten per cent of the adolescent boys and girls interviewed pointed to their teacher's lack of interest in teaching, and to their ineffectiveness in relating to students in the classroom. They said, "He always comes to class unprepared," "He doesn't seem to care if we learn," and "He isn't even interested in what he is teaching." Adolescent perceptions that the teacher does not care either about getting to know the student or about his subject matter encourage a lack of classioom involvement on the part of the student.

Moreover, some teachers treat adolescents as objects of manipulation rather than as human beings with which to relate honestly and sincerely. Such teachers are concerned that the adolescent not view their "seamy sides." For instance, the adolescent should not know that teachers smoke in the furnace room, that they drive cars rapidly, and that they enjoy sensational movies. The irony is that adolescents usually know these things about the teachers, and the teacher's inconsistencies lead to a feeling among youth that teachers are phony, distrustful, and not interested in youth. Teachers establish more respect from youth when they behave as adults and confront the adolescent directly with what their prerogatives are as adults and what the limitations are for the adolescent because he is young. To live by such a double standard, so long as both parties are aware of it, may be better than glaring inconsistencies between verbal platitudes and actual behaviors.

\section{Teachers showing partiality for other students.}

Here about five per cent of the interviewees, mostly boys, said about their teachers, "They have their pets," "Many girls get away with murder-simply because they are girls," and "You have to 'brown-up' the teacher to do well." Teachers, sometimes, are not cognizant of the role they play in influencing a student's relationships with his peers. The teacher's own behaviors and feelings toward a student contribute toward the acceptance of that student by his peers. If the teacher himself accepts each student as an individual-understanding his limitations and giving him support to expand his strong points and help overcome his shortcomingsmembers of the peer group often will tend to follow a similar pat- 
tern. If, on the other hand, the teacher supports primarily the highly competent adolescents and shows rejecting or disapproving behavior to those who are not so successful, a competitive, nonsupportive peer climate is likely to emerge in the classroom. Such atmospheres do not facilitate adolescent self-development. Adolescents who experience successful and secure relationships with their peers achieve more highly on academic tasks, have higher selfesteem, and more positive attitudes toward school than adolescents with poor peer relations. ${ }^{2}$

\section{Concerns with Peers}

Specific concerns over relationships with peers were brought up by about thirty per cent of the entire sample. Even though parents and teachers were mentioned more often, concerns with peers evoked a similar amount of strong feeling. Many different concerns were expressed but only two categories of responses occurred very frequently.

\section{Personal values clashing with those of friends.}

The most typical concern dealt with discontinuities between one's own values and those of others. Comments expressing this problem were, "I don't always agree with them and it bothers me," "Sometimes you can't convince kids that they're wrong," and "I don't agree with what some of the girls do on dates." These concerns demonstrate the tension which adolescents experience as they attempt to develop their own values and self-concepts.

\section{Difficulty in retaining friends and popularity.}

Statements which were about as frequent as those on value conflicts had to do with friendship and popularity. Examples of statements in this category were, "It's hard to know what you have to do to be popular," "I'm very nervous about losing friends," and "I'm afraid that I won't be respected by other kids."

These two categories of concerns are closely interrelated. The adolescent begins to find out who he is and what his values are by intimately relating with others. Peers are the most available persons for intimate relationships. They have similar needs, conflicts, terminology, and interests. At the same time, conflicts naturally

${ }^{2}$ Schmuck, Richard, "Some Relationships of Peer Liking Patterns in the Classroom to Pupil Attitudes and Achievement," The School Review, Vol. 71, No. 3, Autumn, 1963, pps. 337-359. 
arise between peers as to the "right values and beliefs for me." Only through intimate sharing and introspection can the adolescent solve these conflicts for himself. His concern about being detached from friends stems from his fear that he will not be able to figure out who he is without assistance. Provided the adolescent has given up on adults in this regard, peers are the only relevant and available figures who remain.

\section{Adolescent Concerns As the Social Psychologist Sees Them}

My experiences with the working and middle-class adolescent of today indicate that he is not extremely rebellious and intransigent. His stated concerns involve relationships with other people, primarily parents, teachers, and peers. His problems center on integrating the simultaneous, and often inconsistent, demands of these three groups of people. The most basic issue for the adolescent is the attempt to achieve a sense of autonomy and individuality. Both this end of shaping an individuality and the means of reaching it, interacting with important others, are sources of concern.

In the junior and senior high school years, youngsters move through a developmental period of transition between childhood and adulthood. During this time, the adolescent structures his sense of who he is and how valuable he is; his self-concept and selfesteem take on a unique form. As the adolescent experiences this transition, the impressions he has of himself are tractable and his anxieties about how valuable he is are heightened. He is at the crossroads of developing an identity. At this point, he can become several selves, he can cherish several different goals for himself. The demands of parents, teachers, and peers somehow have to be joined and integrated to help in the development of a coherent self picture.

The interpersonal concerns of this period are heightened by the adolescent's physical development-biologically he is an adult during the high school years. He looks to parents and teachers as models for expectations about and ways of expressing his maturing urges. Adults often respond by being aloof and unsympathetic to these feelings. The adolescent then looks to peers as "safe objects" for trying out these new awarenesses. Perhaps the most outstanding feature which is easily visible during this period is the adolescent's self-consciousness about his clothing. If he does not feel properly dressed, or more importantly if he does not feel personally attractive, the adolescent feels inadequate. In fact, the conformity in 
dress, which is also widespread in adult culture, appears to stem in part from a fear of public criticism and loss of support and affection from others.

While the adolescent seeks security in his relations with peers, he also searches for a sense of competence and self efficacy. The achievement of competence and personal effectiveness becomes more difficult as the complexity of contemporary times increases. Indeed, in part at least, the adolescent's problems of becoming an integrated individual can be understood as a function of contemporary social changes. The most obvious change involves increased bureaucratization and the complexity of face to face relationships with various individuals and occupants of roles. One method of coping with the ever increasing sphere of interpersonal relationships that occur in the bureaucratic setting is psychological distance or impersonality. The adolescent who is trying to find intimacy and human affect with teachers and peers often finds superficiality and phoniness instead. Learning to be intimate with someone outside the family is a critical part of self-development. If satisfactory contacts are not available, the adolescent either withdraws or, more commonly, takes on the defensive aloofness and superficiality of his models.

While relationships with parents are very important for the adolescent, more and more I have come to the conclusion that relationships with teachers and peers also play a major part. In a recent study of junior and senior high school students, Van Egmond and I found that the perception of teacher emotional support was by far the most potent facilitator of academic performance in both sexes. ${ }^{3}$ In fact, a high school pupil's relationships with his teacher was the most significant indicator of his school adjustment. The perception that one is respected by the peer group was the second most important facilitating variable. The perception that one's parents felt positive toward school was least important among these three variables, especially for boys. For girls, the perception of parental attitudinal support of school was, however, still significantly related to academic performance.

The most concise way of summing up the psychological basis of adolescent concerns with parents, teachers, and peers is to point to

\footnotetext{
${ }^{3}$ Schmuck, Richard and Van Egmond, Elmer, "Sex Differences in the Relationship of Interpersonal Perceptions to Academic Performance," Psychology in the Schools (in press).
} 
the incessant attempt of the adolescent to establish a consistent picture of himself and to achieve a sense of self-esteem. Every adolescent makes use of the reactions of these other people in formulating his opinion of himself. He relies on them for the gratifications and rewards which make him feel worthwhile and esteemed, or for the punishments and disapproval which make him feel inadequate and worthless. It is primarily parents, teachers, and peers-in person or in the images the adolescent holds of them-who are able to make him feel secure and happy or lost and alienated. The adolescent strives to see himself as competent, respected, and effective in intimate interpersonal relations. If he sees himself this way-if he thinks others see him this way-he can continue the process of self-development and move toward a healthy level of personal esteem.

\section{ConClusions}

Observations and interviews collected over the last five years indicate that working and middle-class adolescents are not alienated from adults. They are not retreating from, or rebelling against, adult society; they are not against school achievement and the core values of the society. Adolescents are, however, struggling with the integration of interpersonal messages and appraisals from parents, teachers, and peers. They are attempting to pull these diverse inputs together into an autonomous and consistent picture of themselves.

The adolescent works out this integration through his intimacies with important others, most often peers in contemporary society. Teachers and peers can play a special part during this transitional period in assisting the adolescent in moving beyond the family. At the same time, the adolescent requires guidance from parental models. Parents and youth need to work more creatively to find ways of sharing their most meaningful and personal thoughts and experiences. The adolescent is in need of discussion with what he perceives to be trustworthy and forthright adults, whether they be teachers or parents. Moreover, the adolescent needs to be supported in his intimate sharing with peers and personal introspection about self. The contemporary adolescent builds a coherent picture of self with least pain and most satisfaction when he is allowed intimacy with peers within the context of mature and honest guidelines from both parents and teachers. 